\title{
Obesity, body fat distribution and breast cancer
}

\author{
Julie A. Lovegrove \\ Hugh Sinclair Unit of Human Nutrition, School of Food Biosciences, The University of \\ Reading, Whiteknights, PO Box 226, Reading RG6 6AP, UK
}

\begin{abstract}
Strong epidemiological data exists implicating anthropometric risk factors in breast cancer aetiology. In premenopausal women the risk of breast cancer increases with increased height, yet decreases with increasing weight and BMI. Although the evidence is not strong, a counter-intuitive positive relationship between central adiposity and premenopausal breast cancer risk is emerging. In post-menopausal women an increased risk in breast cancer has been found for all anthropometric measures: height, weight, BMI, measures of central adiposity (waist:hip ratio and waist circumference) and weight gain, with breast size being a possible additional risk factor. Weight loss as a strategy for reducing breast cancer risk seems to offer a viable prophylaxis in obese post-menopausal women, although data are limited. The evidence for anthropometric measures in relation to breast cancer risk is consistently stronger for post-menopausal women compared with premenopausal women and seems to be dependent on age. A number of possible biological mechanisms have been offered to explain the link between breast cancer risk and anthropometric measures. It has been hypothesised that obesity, especially central fat deposits, linked to insulin resistance, increases circulating hormones such as oestrogens, androgens, insulin, insulin-like growth factor-1 (IGF-1), and decreased levels of hormone-binding proteins such as steroid hormone-binding globulin and IGF1 binding protein- 1 . Thus there are resulting increased concentrations of bioavailable sex hormones, which have been linked to increased breast cancer risk. As obesity is an important modifiable risk factor, which has been linked to increased post-menopausal breast cancer, public health recommendations to maintain ideal weight throughout life are warranted.
\end{abstract}

\section{Obesity: Breast cancer: Anthropometric risk factors: Steroid hor- mone-binding globulin: Oestrodiol: Insulin}

\footnotetext{
Abbreviations: DHEA, dehydroepiandrosterone; DHEAS, dehydroepiandrosterone sulfate; IGF, insulinlike growth factor; IGFBP, insulin-like growth factor binding proteins; NEFA, non-esterified fatty acids; NIDDM, non-insulin-dependent diabetes; RR, relative risk; SHBG, sex hormone-binding globulin.

Corresponding author: Dr J. A. Lovegrove, fax +44 118931 0080, email j.a.lovegrove@afnovell.reading. ac.uk
} 


\section{J. A. Lovegrove}

\section{Introduction}

Recent statistics show that breast cancer has overtaken lung cancer as the most common form of cancer in women in the UK. There are now an estimated 39500 new cases of breast cancer diagnosed in the UK every year and the incidence is still increasing. Unlike many cancers, breast cancer occurs almost exclusively in women. This emphasises the exceptionally high incidence of breast cancer on a population level, compared with lung cancer, which occurs in both sexes. Breast cancer is usually categorised as two separate diseases defined by the time of occurrence: premenopausal or post-menopausal breast cancer. There are many factors implicated in the aetiology of human breast carcinomas, but some of these influence the two forms to differing extents. Menses (timing of menstruation commencement) and parity are significant risk factors; early menarche, late menopause and nulliparity are associated with increased risk in premenopausal breast cancer, whereas multiparity decreases the risk of post-menopausal breast cancer (Moore, 1983; Kaaks, 1996). This is believed to reflect differences in exposure to mammogenic hormones and predominantly reflect adverse effects of prolonged or excessive exposure to oestrogen. Heritage also seems to be an important contributor to risk; having a twin or first-degree relative with breast cancer substantially increases risk. The identification of inherited susceptibility genes BRCA1 and more recently BRCA2 (Sellers, 1997) in inherited cancer will help improve identification of women at high risk of breast cancer, enabling them to receive appropriate prophylactic advice and treatment.

Although diet, especially dietary fat intake, has been implemented in the aetiology of human breast cancer in the past (Lea, 1966; Carroll, 1975), this specific dietary relationship is now generally refuted, due to the inability of data from rigorous controlled human studies to support the epidemiological, and animal evidence (Department of Health, 1998). It is now believed that dietary fat intake is a marker for other more important risk factors, such as body fatness. Over-nutrition resulting in overweight and obesity has been reported to be differentially associated with premenopausal and post-menopausal breast cancer. The evidence illustrating the strong consistent positive association between obesity and post-menopausal breast cancer and the weaker negative relationship between obesity and premenopausal breast cancer will be discussed in the present review. In terms of breast cancer incidence, this relationship with body weight is important, as this is a risk factor that is modifiable. The possible biochemical mechanisms, which may contribute to the differential association of over-nutrition presenting as obesity and central fat accumulation with pre- and post-menopausal breast cancer risk, will also be considered in the present review.

\section{Obesity and disease risk}

Obesity is increasing in prevalence in Western societies. It is claiming 30000 lives annually in England and since estimates suggest that $25 \%$ of women could be obese by 2005 (House of Commons Public Accounts Committee, 2002), this increasing prevalence is a cause for concern. Overweight or obese individuals have an increased risk of developing a number of chronic diseases including cardiovascular disease (Higgins et al. 1989), diabetes (Borrelli et al. 1988) and some cancers (Wolk et al 2001). There is strong evidence that excess body weight increases the risk of cancers at several sites including kidney, endometrium, colon, gallbladder and breast cancer in post-menopausal women (Bergström et al. 2001). A meta-analysis estimated that some 36000 cases of cancer could be avoided by halving the prevalence of overweight and obesity in Europe (Bergström et al. 2001). Moller et al. (1994) reported that obesity was associated with inverse relative risk (RR) of developing breast cancer in subjects under the age of 49, although 
they confirmed a significantly positive RR in subjects over the age of 80 years (Moller et al. 1994). This study and others demonstrate that menopausal status and/or age can be an important determinant in the influence of body weight on breast cancer risk. The evidence linking obesity and breast cancer is sometimes conflicting mainly due to this differential effect of obesity on premenopausal and post-menopausal breast cancer risk. Some studies have not separated women into menopausal state (Schapira et al. 1990; Petrek et al. 1993), which undoubtedly adds to the confusion over the relationship between breast cancer and body fatness. In 1998 the Department of Health published a report on the Nutritional Aspects of the Development of Cancer (Department of Health, 1998). Within this report it was stated that there was a weak negative association between overweight and obesity and premenopausal breast cancer, but a strongly consistent body of evidence for a positive association between BMI (weight $(\mathrm{kg}) / \mathrm{height}(\mathrm{m})^{2}$ ) and post-menopausal breast cancer, although the RR were small (Department of Health, 1998). It reported increasing evidence for a specific association between central adiposity and a higher risk of post-menopausal breast cancer. To date these views are still held, although there is increasing evidence that central adiposity may also be positively associated with premenopausal breast cancer (Huang et al. 1999; Sonnenschein et al. 1999; Muti et al. 2000). The link between anthropometric measures and the two forms of breast cancer; namely pre- and post-menopausal, is summarised in Table 1 and will be discussed in separate sections in the present review.

\section{Premenopausal breast cancer risk}

\section{BMI and premenopausal breast cancer}

Although the literature is not always consistent there is a consensus of opinion that there is a significant negative association between BMI (as an index for obesity) and premenopausal breast cancer (Friedenreich, 2001). Although statistically significant, the relationship was found to be non-linear with a risk of 0.54 (95 \% CI 0.34, 0.95) reported for women with a BMI greater than $31 \mathrm{~kg} / \mathrm{m}^{2}$ compared with a BMI less than $21 \mathrm{~kg} / \mathrm{m}^{2}$ (van den Brandt et al. 2000). It has been reported that data are relatively consistent in case-control studies, but less consistent for cohort studies (Cold et al. 1998; Friedenreich, 2001). Yet data from studies of different designs cannot be equally weighted, when assessing RR. Case-control studies have inherent weaknesses, using self-reported anthropometric measures rather than accurately measured values in cohort studies. In addition some of these studies had relatively small numbers, which could also have been a limiting factor.

Several reports have attempted to clarify the relationship of BMI with the development of premenopausal breast cancer. In a meta-analysis using four cohort studies and nineteen case-control studies published between 1966-1992, Ursin et al. (1995) reported the risk to be

Table 1. Anthropometric measurements and associated risk for pre- and postmenopausal breast cancer

\begin{tabular}{lcc}
\hline & $\begin{array}{c}\text { Premenopausal breast } \\
\text { cancer risk }\end{array}$ & $\begin{array}{c}\text { Post-menopausal breast } \\
\text { cancer risk }\end{array}$ \\
\hline Weight & - & ++ \\
Height & + & ++ \\
BMl & - & ++ \\
Central fat deposition & + & ++ \\
Breast size & + & + \\
\hline
\end{tabular}

+ , Increased risk; -, decreased risk. 
$0 \cdot 7(95 \%$ CI $0 \cdot 54,0 \cdot 91)$ for the cohort studies and $0 \cdot 88$ (95\% CI $0 \cdot 76,1 \cdot 02)$ for the case-control studies comparing thin and obese women (difference of $8 \mathrm{~kg} / \mathrm{m}^{2}$ ) and reached the conclusion that there was a significant trend for decreased RR for premenopausal breast cancer in association with increased BMI. This was supported by probably the strongest data to date, from the Pooling Project in Diet and Cancer (Hunter et al. 1996; van den Brandt et al. 2000). This study reported on the re-analysis of the original, individual-level data from seven prospective cohort studies conducted worldwide. An impressive 337819 women and 4385 incident invasive breast cancer cases were included. It was reported that compared with women with a BMI of less than $21 \mathrm{~kg} / \mathrm{m}^{2}$, women with a BMI greater than $31 \mathrm{~kg} / \mathrm{m}^{2}$ experienced a risk of $0.54(95 \%$ CI 0.34 , $0 \cdot 95$ ) and it was concluded that there was a significant negative association between BMI and premenopausal breast cancer. Using a different approach, Pathak \& Whittemore (1992) evaluated seven populations representing subjects considered to be at high (women from USA), medium (women from Brazil, Greece and Yugoslavia) or low (women from Taiwan and Japan) risk for the development of breast cancer. They concluded that the inverse relation of BMI and the RR for development of premenopausal breast cancer was only characteristic of populations that were reported to be at high risk for this type of cancer, while a positive relationship was demonstrated for populations of low risk from premenopausal breast cancer.

The conclusions of Pathak \& Whittemore (1992) that the negative association between BMI and premenopausal breast cancer applies only in high-risk populations is intriguing, and requires further investigation. Literature on the association between BMI and premenopausal breast cancer in groups at lower risk is limited, as little research has been completed in these populations. However a study performed by Ziegler et al. (1996) investigated Asian-American women (Chinese, Japanese or Filipino) who in their country of origin are reported to have a 4-7-fold lower risk from breast cancer then Western natives. In this group premenopausal breast cancer risk was found to be lower in heavy American-Asian women, which is consistent with data from studies investigating American-Caucasians, but not consistent with the idea that low-risk women have the opposite relationship between BMI and breast cancer. The consistent relationship between breast cancer risk in Asian-Americans and Caucasian-Americans may be due to a similar relationship between BMI and premenopausal breast cancer in high- and low-risk groups. However, conversely, an explanation for the data of Ziegler et al. (1996) could be that populations emigrating to Western societies (such as the USA) take on risk characteristics and statistics of the new population, rather than retaining that of their native populations, which has been reported for other chronic diseases such as cardiovascular disease. However a recent population-based case-control study among Chinese women in urban Shanghai (a group at low risk of breast cancer development) presenting with breast cancer reported that there was no relationship between BMI and premenopausal breast cancer risk (Shu et al. 2001). Whether this reflects the weaknesses of the study design (case-control) or an actual lack of association is yet to be determined. However Shu et al. (2001) did report that waist:hip ratio (a measure of central obesity) was positively related to an increased risk of premenopausal breast cancer (odds ratio $=1.7$ for the higher compared with the lowest category). This positive association between measures of central fat accumulation and premenopausal breast cancer, but a negative association with total body fat and premenopausal breast cancer risk, seems counter-intuitive and is discussed in more detail in the section on possible mechanisms (see p. 398).

\section{Time of weight gain and premenopausal breast cancer}

Another important consideration is the time at which body weight measurements are recorded relative to diagnosis, as this may have significant bearing on the association with breast cancer 
incidence. However in the case of premenopausal women the inverse association between BMI and breast cancer seems evident, regardless of whether weight is assessed at time of diagnosis, soon after or at an earlier time (i.e. during childhood, adolescence or adulthood) (Hislop et al. 1986; London et al. 1989; Brinton \& Swanson, 1992; Ursin et al. 1995). Earlier studies found that the inverse association between relative weight and breast cancer risk in premenopausal women was limited to women with small tumours (Willet et al. 1985; Swanson et al. 1989). However subsequent analysis suggests that detection bias does not explain the increased risk for breast cancer observed among lean premenopausal women (London et al. 1989; Brinton \& Swanson, 1992; Tornberg \& Carstensen, 1994).

\section{Weight and premenopausal breast cancer}

In addition to this negative association between BMI and premenopausal breast cancer, most data also suggest a negative association between body weight and risk for breast cancer (Friedenreich, 2001). This is not an unexpected finding as weight is one of the variables of BMI. As with the association between BMI and premenopausal breast cancer risk the evidence is stronger for case-control studies than for prospective cohort studies (Cold et al. 1998). The explanation for this is that inconsistencies found in cohort studies may be attributable to some methodological limitations inherent in those study designs. Since weight was sometimes measured at baseline and not re-measured during follow-up assessments, and because women gain weight as they age, the ability to detect an association between weight measured several years before diagnosis may be diminished. The data from the Pooling Project on Diet and Cancer reported an inverse association, with a risk of 0.58 (95\% CI 0.40, 0.83) among women weighing $80 \mathrm{~kg}$ or more compared with those weighing $60 \mathrm{~kg}$ (van den Brandt et al. 2000).

\section{Height and premenopausal breast cancer}

The other variable used for the calculation of the BMI is that of height. Most studies have found a positive association between breast cancer and height (Ballard-Barbash, 1994; Cold et al. 1998; van den Brandt et al. 2000). For this anthropometric parameter evidence from cohort studies is stronger than that from case-control studies. This could be a reflection of methods of data collection, with cohort studies usually reporting measured height whereas case-control studies used self-reported height. Among those studies that were able to examine risk by menopausal status, a weaker positive association was reported for premenopausal women (Ballard-Barbash, 1994; Department of Health, 1998). It was concluded by the Department of Health Report on Nutritional Aspects of the Development of Cancer that there was no clear association with height and premenopausal breast cancer risk (Department of Health, 1998). The range of risks estimated for taller compared with shorter premenopausal women was 0·8-12.0 (Ballard-Barbash, 1994). Data from the Pooling Project showed a lower, but significant, relationship between height and premenopausal breast cancer. It expressed the risk in a different form; the RR of breast cancer per height increment of $0.05 \mathrm{~m}$ was 1.02 (95\% CI 0.96, 1.10) in premenopausal women (van den Brandt et al. 2000). Another report on AsianAmerican women also observed increases in risk with increased height (RR of $2 \cdot 0$ over $0 \cdot 18 \mathrm{~m}$ range in height $(<1.51 \mathrm{~m} \rightarrow>1.66 \mathrm{~m}))$ (Ziegler et al. 1996).

An increased risk of premenopausal breast cancer and height has been observed worldwide. However stronger associations have generally been found in populations that have limited 


\section{J. A. Lovegrove}

energy intake in childhood and adolescence, which limited growth. This is true for developing countries and populations that experienced acute food shortages such as during and after World War II in Europe (Vatten \& Kvinnsland, 1990). The explanation for this association may be due to childhood energy intake (with height as an indicator) being associated with a number of other risk factors. One of these may be mammary mass, which may be a significant risk factor for breast carcinomas (Swanson et al. 1988; Hunter \& Willet, 1993), or increased insulin resistance.

\section{Body fat distribution and premenopausal breast cancer}

The location of body fat, especially centrally, has been found to have a positive association with a number of diseases. Female upper body obesity (central or abdominal obesity) has been reported to be associated with increased risk of mortality (Folsom et al. 1993) especially from cardiovascular disease and diabetes (Van Noord et al. 1990; Zamboni et al. 1997). Recent interest has also focused on body fat distribution to help elucidate the relationship between obesity and breast cancer risk. Direct imaging techniques such as computerised tomography, magnetic resonance and dual energy X-ray absorptiometry are the most accurate techniques to estimate total and regional fat deposits (Armellini et al. 1996). However due to expense, practicality and availability of equipment, many large population studies have relied upon indirect measures of these fat depots. Although waist:hip ratio has been the most commonly used measure for abdominal fat depots, waist is now emerging as the more favoured measure. Waist has been identified as the strongest correlate of both degree of obesity and visceral fat deposit when different anthropometric measurements were compared with direct imaging techniques (Molarius \& Seidell, 1998). Therefore it is important to bear in mind that comparison of studies that use different methods for determining different fat deposits may be inappropriate, although with no alternative, rational conclusion must be made from the available data. Although the evidence is again not consistent, the majority of studies report a positive association between central adiposity and premenopausal breast cancer risk. Ballard-Barbash et al. (1990) reporting on the 2201 women participating in the Framingham study stated that only women in the highest quartile for central to peripheral body fat distribution (calculated from the sum of the trunkal skinfolds: chest, subscapular and abdominal, divided by the sum of the extremity skinfolds: triceps and thigh) demonstrated an increased risk of breast cancer of 1.8 (95\% CI 1.2, 2.6) irrespective of menopausal status. Schapira et al. (1990) reported that breast cancer subjects with no designated menopausal status had a higher waist:hip ratio than did control subjects. Recent reports of prospective cohort studies from the ORDET (Hormones and Diet in the Etiology of Breast Cancer) study, on breast cancer in Italy (Muti et al. 2000) and the New York University Women's Health Study (Sonnenschein et al. 1999) have shown a significant positive association between waist:hip ratio and premenopausal breast cancer risk of $2 \cdot 2(95 \%$ CI $1 \cdot 0,4 \cdot 8)$ and $1 \cdot 7(95 \%$ CI $1 \cdot 0,3 \cdot 1)$ respectively. Huang et al. (1999) reported a non-significant positive relationship between waist circumference and premenopausal breast cancer in the prospective cohort study of 47382 US registered nurses reporting anthropometric measurements in 1986 and in 1994 for identification of incident cases of breast cancer. However, both reports from the prospective cohort study of 11663 women in a breast-cancer screening programme (the DOM (Doorlopend Onderzock Morbiditeit en Mortal)) project in Utrecht, Netherlands) reported an equivocal association between fat distribution (measured as waist-to-hip ratio) and premenopausal breast cancer (den Tonkelaar et al. 1995; Kaaks et al. 1998). The inconsistencies in the literature may relate to varying methods used to measure central fat. However despite these inconsistencies, there is a growing body of evidence that supports a weak positive association between central fat accumulation and premenopausal breast cancer risk. 
Post-menopausal breast cancer risk

BMI and post-menopausal breast cancer

Following early animal experiments, which demonstrated that the incidence of breast tumours increased when mice were fed diets high in energy and fat (Tannenbaum, 1942), de Waard et al. (1964) postulated that over-nutrition and obesity were key determinants of post-menopausal breast cancer. The evidence for obesity in post-menopausal breast cancer risk is becoming stronger. As with weight, BMI showed a significant positive association in post-menopausal women in the Pooling Project analysis. The risk of post-menopausal breast cancer at or above a BMI of $28 \mathrm{~kg} / \mathrm{m}^{2}$ was 1.26 (95\% CI 1.09, 1.46) compared with a BMI below $21 \mathrm{~kg} / \mathrm{m}^{2}$. However the risk did not increase after this weight, confirming a non-linear relationship (van den Brandt et al. 2000). Some studies are consistent with these observations, although inconsistencies in data are also evident (Friedenreich, 2001). The report from the Department of Health on the Nutritional Aspects of the Development of Cancer reported a consistent body of evidence for a positive association between BMI and post-menopausal breast cancer, although the RR were small (Department of Health, 1998). This association was reported to be statistically stronger than the association with premenopausal breast cancer and supports previous reports (Pathak \& Whittemore, 1992; Cleary \& Maihle, 1997).

Inconsistencies in the literature could be due to a number of confounding factors. Factors that have been identified as confounding include those of small sample size, populations with a narrow range of weight and BMI and the age of the population studied (Ballard-Barbash, 1994). The evidence for age as an important factor in the interaction of body weight and postmenopausal breast cancer risk is strong (Peacock et al. 1999). Although Moller et al. (1994) reported that obesity was associated with inverse RR of developing breast cancer in subjects under the age of 49 , they confirmed a significantly positive RR in subjects over the age of 80 years. This study, amongst others, identified age as an important determinant in the influence of body weight on breast cancer. Results from a re-analysis of combined data from three Italian studies included more than 3000 post-menopausal breast cancer subjects over 50 years of age (La Vecchia et al. 1997) and reported a significant increased risk of 1.4 for BMI quintiles ranging from $<21 \cdot 8-28 \cdot 4 \mathrm{~kg} / \mathrm{m}^{2}$. However when subjects were divided into three age categories (50-59, $60-69,>70$ years of age) a significant increase in RR for breast cancer was only observed in the youngest and oldest group. Ziegler et al.'s (1996) case-control study on Asian-American women also investigated age as a variable and concluded that trends in risk became more striking as adiposity in each succeeding decade of life was considered. It could be concluded from the evidence of these well-controlled studies that the effect of BMI on risk of post-menopausal breast cancer does depend on age. If obese premenopausal women have a reduced risk of breast cancer with increased obesity, which has been reported, then it seems unlikely that obese women would suddenly have a higher risk immediately after menopause. It seems plausible that it would take time before the increased risk of breast cancer in the post-menopausal obese women outweighs the previous protective effect observed in premenopausal women.

Yong et al. (1996) investigated the issue of the timing of weight recording. It was reported that the RR for developing post-menopausal breast cancer was not associated with BMI calculated from premenopausal height and weight, but from the higher BMI calculated from height and weight obtained after menopause, which was a positive risk factor (Yong et al. 1996). The issue of weight recording and post-menopausal breast cancer could be an important factor contributing to the weaker relationship between BMI or weight and post-menopausal breast cancer risk in cohort studies compared with case-control studies (van den Brandt et al. 2000). In cohort studies, the long interval between weight assessment and diagnosis allows a greater 
interval for weight change and perhaps results in greater misclassification of women in relative weight categories (Ballard-Barbash, 1994). In addition to time of weight recording, weight changes throughout life have been investigated. Contrary to results from premenopausal breast cancer risk, timing of weight gain has been found to have significant influence on postmenopausal breast cancer risk (Ballard-Barbash, 1994; Cold et al. 1998; Department of Health, 1998; Friedenreich, 2001). It has been suggested that excess weight gain may function as a late stage promoter of breast carcinogenesis, although this requires further investigation (Zeigler $e t$ al. 1996).

\section{Height and post-menopausal breast cancer}

It has been estimated by Ballard-Barbash (1994) that the overall range of risks for breast cancer for taller compared with shorter post-menopausal women is $1 \cdot 3-1 \cdot 9$, with an increased risk in those women with a family history (RR of about $2 \cdot 0$ ). The most recent and comprehensive assessment of height and breast cancer risk is the Pooling Project of Diet and Cancer. After multivariate analyses controlling for reproductive, dietary and other risk factors the pooled RR of breast cancer per height increment of $0.05 \mathrm{~m}$ was 1.07 (95\% CI 1.03, 1.12) in postmenopausal women (van den Brandt et al. 2000). These data support most previous studies investigating breast cancer and height (Cold et al. 1998). As for premenopausal breast cancer risk and height, evidence from cohort studies is stronger than the case-control studies as cohort studies use measured height, whereas case-control studies rely on self-reported values (Friedenreich, 2001). Yet the balance of evidence suggests that the relationship between height and breast cancer risk is stronger for post- compared with premenopausal women (Department of Health, 1998).

\section{Timing of weight gain and post-menopausal breast cancer}

Adult weight gain has been linked consistently to an increased risk for post-menopausal breast cancer (Ballard-Barbash, 1994) even in cohort studies that have found no association between relative weight at baseline (London et al. 1989; Ballard-Barbash et al. 1990; Folsom et al. 1990). In addition, the effect of adult weight gain and disease has been independent of relative weight in most analyses (London et al. 1989; Ballard-Barbash et al. 1990; Folsom et al. 1990). It has also been reported that the magnitude of excess risk was greater for adult weight gain than for higher recent body weight (Le Marchand et al. 1988; Kumar et al. 1995; Huang et al. 1997). Consistent findings of a positive relationship between weight gain and post-menopausal breast cancer risk have been reported despite the heterogeneity among studies in the definitions of weight gain, use of weight gain $v$. increases in BMI and relevant ages (Trentham-Dietz et al. 2000). A case-control study that contained data on weight at various ages found only a slight inverse association between post-menopausal breast cancer and weight at younger age $(15,20$ and 25 years of age), but found an increased risk associated with heavier weight both during menopause and at time of diagnosis that was more striking amongst older post-menopausal women (70 years of age) (Choi et al. 1978). Several studies have indicated that increases in either body weight or BMI status from teenage years until near the time of diagnosis were associated with increased RR for development of post-menopausal breast cancer (Paffenbarger et al. 1980; London et al. 1989; Folsom et al. 1990). However the more important weight gain is that during adulthood and after the menopause. 
The Department of Health has stated that the RR for weight gain of more than $10 \mathrm{~kg}$ was in the order of 2.0 in at least three studies, particularly if individuals were lean in early adulthood (Department of Health, 1998). If menopausal weight is an important marker of risk as evidence suggests, most existing cohort studies are unlikely to demonstrate an association between weight and breast cancer. Many of these studies have recorded weight in the premenopausal period and therefore their weight measures do not include the effect of menopausal weight gain. This may account for the observation that cohort studies often report little, weak or no associations between weight and weight gain and post-menopausal breast cancer risk. It has been postulated that the timing of weight gain may be an important consideration, as excessive weight gain during periods of hormonal change such as puberty, pregnancy, lactation and menopause could have differing physiological effects because of the location of fat deposition during these periods (Stoll, 1999). Weight gain during puberty is predominantly on the hips and buttocks (gynoid), conversely weight gain during pregnancy and menopause is characterised by an increased central fat distribution (android) (Kumar et al. 1995). Stoll has postulated that excessive weight gain during the times of hormonal change may result in metabolic dysfunction leading to hyperinsulinaemia (Stoll, 1995). This will be discussed in more detail later (see p. 404).

\section{Weight loss and post-menopausal breast cancer risk}

Weight loss, particularly later in life, may decrease breast cancer risk (Zeigler et al. 1996; Trentham-Dietz et al. 1997, 2000; van den Brandt et al. 1997; Magnusson et al. 1998). The estimated RR for weight loss has been estimated as 0.8-1.5 (95\% CI) in post-menopausal women (Ballard-Barbash, 1994). However weight cycling, defined as successive weight loss and gain, does not appear to relate to breast cancer risk, although few studies have examined this potential risk factor (Trentham-Dietz et al. 2000).

It has been postulated that the decrease in breast cancer risk due to weight loss could be mediated through changes in hormonal status and body fat distribution (Kumar et al. 1995). An increase in sex hormone-binding globulin (SHBG) has been reported in women after weight loss (Schapira et al. 1994). Women with a predominant central body fat distribution have been shown to have decreased fat cell size after energy restriction, thereby reducing abdominal obesity, reducing breast cancer risk (Schapira et al. 1994).

\section{Body fat distribution and post-menopausal breast cancer}

Location of fat deposition as a separate risk factor for post-menopausal breast cancer has been examined by an increasing number of investigators. Several studies have found that women with a predominant upper body-fat distribution are at an increased risk for post-menopausal breast cancer independent of body weight (Ballard-Barbash et al. 1990; Folsom et al. 1990; Schapira et al. 1990; Sellers et al. 1992; Kumar et al. 1995; Männistö et al. 1996; Ng et al. 1997; Magnusson et al. 1998; Sonnenschein et al. 1999; Hall et al. 2000). Schapira et al. (1990) reported a well-controlled study in which breast cancer patients were matched for age, weight, height, BMI and percentage body fat with control subjects. A higher visceral fat mass assessed by computerised tomography was reported in the breast cancer patients (Schapira et al. 1990). These data support a role for specific locations of body fat in breast cancer development, necessitating the direct measurement of body fat at various sites to investigate the relationship. As mentioned earlier (p. 394) in relation to body fat distribution and premenopausal 
breast cancer, direct measures of fat deposits such as computerised tomography used by Schapira et al. (1990) more accurately quantifies specific fat deposits, which may have differential effects on breast cancer risk. Therefore data from studies using direct measures should be given greater weight than those using less accurate indirect methods such as waist:hip ratio.

In the Nurses' Health Study in women aged 30-55 years at baseline, measures of central adiposity (measured as waist circumference) were moderately associated with post-menopausal breast cancer (Huang et al. 1999). The risk for the highest $v$. lowest quintile of waist circumference was 1.34 (95\% CI 1.05, 1.72). When the analysis was restricted to those who had never taken hormone replacement therapy the RR was increased to 1.88 (95\% CI 1.25, 2.85) and slightly attenuated after controlling for BMI. The risk for waist:hip ratio when fully adjusted including BMI was 1.22 (95\% CI 0.96, 1.55) and when restricted to never using hormone replacement therapy was 1.85 (95\% CI $1.25,2 \cdot 74)$. These results are in agreement with the other prospective studies investigating regional adiposity, measured using indirect techniques, and breast cancer risk, which consistently reported strong associations for post-menopausal breast cancer (Ballard-Barbash et al. 1990; Folsom et al. 1990; Kaaks et al. 1998).

Waist:hip ratio, and especially waist circumference, has been associated with postmenopausal breast cancer in most (Ballard-Barbash et al. 1990; Schapira et al. 1990; Bruning et al. 1992; Männistö et al. 1996) but not all (den Tonkelaar et al. 1992; Petrek et al. 1993) case-control studies. Waist circumference has been found to be a stronger predictor of breast cancer risk (Huang et al. 1999) and also for cardiovascular risk factors than waist:hip ratio (Lovegrove et al. 2002). The pattern of abdominal fat deposition is believed to be genetically determined and is associated with multiple hormonal and metabolic changes, including insulin resistance, hyperinsulinaemia, decreases in SHBG, increases in androgen levels and the conversion of androgen to oestrogen in adipose tissue (Ballard-Barbash, 1994), possibly explaining the reports of an increased risk of breast cancer with central rather than peripherally distributed fat.

\section{Breast size}

Breast size is considered a plausible proxy for volume of breast tissue at risk. The fat depots in the breast also contribute to local oestrogen concentrations and may act as a repository for lipid soluble carcinogens (Kohlmeier \& Kohlmeier, 1995). The literature is inconsistent, since although the majority of studies have not reported an association between breast size and risk, there are a few studies that have found a positive association between breast size and breast cancer risk (Dupont \& Page, 1987; Hsieh \& Trichopoulos, 1991; Egan et al. 1999). The possible reasons for the lack of an association of several studies has been attributed to small sample size, lack of control for adiposity and misclassification of the exposure, since breast size after, rather than before, childbearing was used (Egan et al. 1999). Egan et al. (1999) found an increased risk of breast cancer only among women who were large-breasted, lean as young adults and had a small back circumference (chest size under 34 inches). More controlled studies are required to clarify the relationship between breast size and breast cancer risk.

\section{Possible mechanisms of breast cancer risk and obesity}

The increased risk of premenopausal and especially post-menopausal breast cancer in taller, and more centrally obese women has been discussed in some detail earlier (see pp. 393 and 396). The possible mechanism involved in the relationship between increased adiposity, 
Table 2. Possible mechanisms involved with obesity and breast cancer risk

\author{
Mechanisms \\ Reduced detection of tumour, late diagnosis \\ Increased free bioactive oestrogen levels* \\ Increased androgen levels* \\ Increased extraglandular conversion of androgens to oestrogens \\ Decreased steroid hormone binding globulin \\ Increased growth factors (i.e. insulin-like growth factor ${ }^{*}$ ) \\ Increased receptors for growth factors \\ Decreased specific binding proteins for growth factors \\ Hyperinsulinaemia \\ Increased insulin resistance \\ Elevated non-esterified fatty acids \\ Increased lipid-soluble carcinogens, especially in the breast $^{\star}$
}

*Mechanisms with direct involvement in mammary carcinogenesis.

especially central adiposity, and the risk of breast cancer will be covered later (pp. 401 and 403). Table 2 summarises plausible mechanisms involved in the relationship of obesity and breast cancer.

\title{
Delayed symptom recognition
}

Obesity may be a contributing factor in delayed symptom recognition, which could be linked with the positive association between obesity and late-stage disease in post-menopausal women (London et al. 1989; Schapira et al. 1991; Hall et al. 1999), and breast size and stage of breast cancer at diagnosis (Ingam et al. 1989; Hall et al. 1999). Hall et al. (1999) investigated the relationship between stage of disease, and both BMI and breast size, stratified by method of detection, using data from a population-based case-control study of 1361 women diagnosed with breast cancer. Odds of late-stage disease were increased with BMI, the adjusted odds ratio for highest to lowest tertiles was 1.46 (95\% CI 1.20,1.93), and for larger bra cup size, the odds ratio for cup D $v$. A was $1.61(95 \%$ CI $1 \cdot 04,2 \cdot 48)$. It has been postulated that the association between BMI and disease stage is attributable to delayed symptom recognition in self-detection. However this hypothesis is not supported by evidence from the previously discussed study by Hall et al. (1999), where the increase in late-stage breast cancer with BMI and bra cup size was not modified by detection method. Another study reported that self-examination, as practised by American women in 1959, did not reduce the risk of breast cancer mortality and did not differ according to weight (Holmberg et al. 1997). In another study overweight and obese women were reported to be less likely to be screened for cervical and breast cancer with Pap smears and mammography, even after adjustment for other known barriers to care (Wee et al. 2000). This could contribute to the later stage at diagnosis reported in obese women. Obesity prevalence in different populations (higher among black compared with white American women) has also been identified as playing an important role in the reduced likelihood of cancer being diagnosed at an early stage in these minorities (Jones et al. 1997).

Delayed symptom recognition has also been postulated as a factor contributing to the negative association between BMI and premenopausal breast cancer, reducing the identification of tumours during this period (Willet et al. 1985). However, this hypothesis is not supported by Pathak \& Whittemore's (1992) data, which showed an adverse effect of adiposity among premenopausal women in moderate-risk countries. It is unlikely that obesity would delay cancer recognition in high-risk but not in moderate-risk countries. It was proposed that different BMI 
amongst premenopausal women in different risk groups may reflect different effects of central $v$. peripheral body fat (Folsom et al. 1990).

\section{Sex hormones and breast cancer}

Ovarian hormones, predominantly oestrogens and possibly androgens, have been identified as being important in the aetiology of breast cancer (Kaaks, 1996). MacKenzie (1955) reported the mammary tumour-promoting effects of oestrogens in rodents. Since the 1960s, a large number of case-control studies investigating the relationship between endogenous steroid hormone levels and breast cancer have been conducted, and have been reviewed by Key \& Pike (1988) and Bernstein \& Ross (1993). There is substantial evidence that high plasma levels of available oestrogens (those not bound to protein, either the specific carrier, SHBG or non-specific carrier, plasma albumin) are associated with increased risk of breast cancer, at least amongst postmenopausal women, on whom most studies have focused (Key \& Pike, 1988; Bernstein \& Ross, 1993). Studies reported since these reviews also support this conclusion, with the New York Women's Health Study and the Breast Cancer Serum Bank Study reporting a RR of about 4.0 between the extreme quartiles of plasma free $17-\beta$-oestradiol in post-menopausal women (Toniolo et al. 1995; Dorgan et al. 1996). It has been reported that an early menarche, late menopause, low parity and a late first pregnancy are independently associated with premenopausal breast cancer, with substitutive oestrogen therapy also associated with increased risk (Kelsy \& Bernstein, 1996). The early menarche and late menopause increase the risk of breast cancer due to the increased exposure of the mammary glands to oestrogens and progesterone (Key et al. 2001). A prospective analysis of the Dutch DOM cohort reported strong protective effects of early age of menopause and premenopausal breast cancer (Monninkhof et al. 1999). Although the relationship between timing of pregnancies and breast cancer is not clearly understood, it has been hypothesised that an early first pregnancy and multiparity reduce risk, since sensitivity to the mammogenic effects of hormones is likely to be higher between puberty and the first full-term pregnancy, so that early pregnancies result in a shorter duration of action at this sensitivity (Stoll \& Secreto, 1992). Incidence rates of breast cancer rise less steeply in all populations after the menopause, when ovarian oestrogen production ceases (Key $\&$ Pike, 1988). In post-menopausal women the principal source of oestradiol is from the androgen, androstenedione, which is secreted by the adrenal glands and aromatised by the enzyme aromatase to oestrone in the peripheral tissue, mainly the adipose tissue; some of the oestrone is then converted to oestradiol (Siiteri \& MacDonald, 1973). There is evidence that the relative potency of 17- $\beta$-oestradiol as a cancer-promoting oestrogen is considerably higher than oestrone (De Pergola et al. 1996). However it is indisputable that high levels of bioavailable (or unbound) oestrogen are associated with an increased risk of breast cancer (Toniolo, 2001).

Some workers have postulated that high plasma testosterone is the predominant endocrine anomaly related to an increased risk of breast cancer and, in addition to oestradiol, could be the important endocrine risk factor for breast cancer. These data led to the formulation of the 'ovarian androgen excess' hypothesis (Zumoff, 1988). Since this theory was proposed, data have been accumulating in support of an increased risk from elevated plasma testosterone levels. In addition to the Italian 'ORDET' study that reported a RR of 7.0 between the highest and lowest tertiles of circulating plasma testosterone (Berrino et al. 1996), the Breast Cancer Serum Bank Study reported a RR of $6 \cdot 2$ for the highest $v$. lowest quartile of plasma testosterone in women (Dorgan et al. 1996). The possible mechanisms that may contribute to adverse effects of raised testosterone include: direct stimulation of the mitogenic activity of mammary gland cells, 
which possess the testosterone receptor; the increase in adipose tissue-derived 17 - $\beta$-oestradiol due to aromatisation of testosterone; the stimulation of epithelial growth factor production with the consequential increase in the mitogenic activity of gland cells (Secreto \& Zumoff, 1994). The bioavailability of circulating testosterone levels is proposed to be dependent on the relative bound to unbound testosterone.

An important determinant of available (unbound) oestrogen and testosterone levels is the relative concentration of SHBG, which is synthesised in the liver and has specific binding sites for oestrogens and androgens. Most of the oestradiol and testosterone is protein-bound (about $40-50 \%$ to SHBG and about $40-50 \%$ to albumin) resulting in only about $2 \%$ that is free and available to enter cells and bind to receptors. Since the binding capacity of albumin is very high, the primary determinant of the proportion of the steroid that is free is the concentration of SHBG, with an increase in serum SHBG concentration producing a corresponding reduction in the proportion of free steroid (Dunn et al. 1981). Therefore the SHBG:oestradiol and SHBG:testosterone ratios are significant in relation to the risk of breast cancer development.

In addition to testosterone, other adrenal androgens such as dehydroepiandrosterone (DHEA) and dehydroepiandrosterone sulfate (DHEAS) have also been linked to breast cancer risk. It has been proposed that DHEA in premenopausal women can act as an antagonist of oestrogens, since its metabolite 5-androstene-3, $17 \beta$-diole competes for oestrogen receptors, and has been found to reduce the growth-stimulating effects of $17-\beta$-oestradiol on tissue growth in tissue culture studies (Ebling \& Koivisto, 1994). Therefore the relative proportion of DHEAS:DHEA is now believed by some to be an important consideration, with higher ratios considered to be associated with higher breast cancer risk (Nestler \& Kahwash, 1994).

Although most evidence has suggested that oestrogens are the major steroidal influence in mammary tumourgenesis, it has been proposed that progesterone may be the predominant mitogen for normal epithelium proliferation and that oestrogens (especially $17-\beta$-oestradiol) may potentiate this effect via induction of increased progesterone receptor numbers (Kaaks, 1996). However, in neoplastic epithelium, oestrogens appear to be the more predominant mitogen (Shi et al. 1994). It has been postulated that tumour development is promoted most strongly at a simultaneous exposure to oestrogens plus progesterone (Henderson et al. 1985). This was proposed after the clinical observation that normal epithelium proliferation rates are highest in the luteal phase of the menstrual cycle when both oestrogens and progesterones are high. Although there are inconsistencies in the literature, the progesterone plus oestrogen hypothesis in relation to increased breast cancer risk is now generally accepted.

The mechanism by which sex hormones affect cancer risk is probably largely through determining the number and mitotic rate of the epithelial cells in the breast (Cohen \& Ellwein, 1990). High mitogenic rates can increase the chance of mutations occurring and of being replicated before repair has taken place, which in addition to increasing the growth of early tumours can increase cancer development (Cohen \& Ellwein, 1990). Liehr (2000) also hypothesised that metabolites from oestradiol could directly effect DNA mutations, although this is probably of minor significance (Key et al. 2001).

\section{Obesity, sex hormones and breast cancer risk}

It is known that adipose tissue is not an inert fat store but an endocrine organ responsible for, amongst others, steroid hormone metabolism. Due to an enzymic complex (cytochrome-P450dependent aromatisation) adipose tissue is able to convert androstenedione to oestrone and testosterone into 17- $\beta$-oestradiol (De Pergola et al. 1996) as discussed earlier. Oestrogens syn- 
thesised by the adipose tissue represent around one third of the total plasma oestrogens in premenopausal women; yet after the menopause they represent the major single source of circulating oestrogens. Therefore any increase in fat mass would have a greater impact on the total oestrogen concentrations in post-menopausal, compared with premenopausal women.

Excessive body weight has a significant influence on hormone levels in both pre- and postmenopausal women. In premenopausal women concentrations of oestrogens and androgens are homeostatically controlled through feedback loops involving the hypothalamus and anterior pituitary respectively. However serum total oestradiol levels were shown to decrease with increasing BMI in premenopausal women (Potischman et al. 1996) or to be unaffected (Verkasalo et al. 2001). In contrast to premenopausal women, among post-menopausal women oestrogens are largely produced by conversion in adipose and other tissue and are not controlled by any feedback mechanisms (Key et al. 2001). In post-menopausal women free oestrogen levels are higher in obese compared with non-obese women (Nagata et al. 2000; Key et al. 2001; Verkasalo et al. 2001) due in part to the increased plasma testosterone concentrations (Evans et al. 1983; Kirschner et al. 1990; Krotkiewski et al. 1990; Kaye et al. 1991) and decreased concentrations of SHBG (Kirschner et al. 1990; Schapira et al. 1991; Maggino et al. 1993; Kissebah \& Krakower, 1994). Numerous studies have shown without exception that the plasma concentration of SHBG falls with increasing BMI, with SHBG concentrations in thin women (BMI $<20 \mathrm{~kg} / \mathrm{m}^{2}$ ) approximately 2-fold higher than large women $\left(\mathrm{BMI}>30 \mathrm{~kg} / \mathrm{m}^{2}\right.$ ) (Key et al. 2001). Although the mechanism for this effect has not been fully elucidated, it may be largely due to the rise in insulin levels with increasing BMI (Franks et al. 1991). Testosterone has a higher affinity for SHBG, and is metabolised to $17-\beta$-oestradiol in adipocytes. Therefore these two mechanisms result in an increase in the free 17- $\beta$-oestradiol concentrations (Kaye et al. 1991; Potischman et al. 1996). The opposite relationship between endogenous oestrogen levels and body weight in pre- and postmenopausal women could explain the differing relationship between obesity and breast cancer before and after the menopause (Carroll, 1998), although this needs further clarification.

Other studies reported that premenopausal women with female pattern obesity had higher oestrone levels than those with male pattern obesity (Kirschner et al. 1990; De Pergola et al. 1996). The explanation for this finding was that the subcutaneous adipocytes preferentially converted androstenedione into oestrone, rather than $5 \alpha$ reduced androgens (androsterone). Subcutaneous adipocytes were reported to have higher levels of mRNA and a higher activity of P450-dependent aromatisation, when compared with visceral adipose tissue (De Pergola et al. 1996). As discussed earlier, central adiposity, but not female pattern obesity was associated positively with an increased risk of premenopausal breast cancer. Therefore it can be concluded from the De Pergola et al. (1996) study that aromatisation of androsterone into oestrone alone is not likely to be a predisposing factor for breast cancer and supports previous data that oestrone is less carcinogenic than 17- $\beta$-oestradiol. However this is at present speculative and requires further clarification.

Another sex hormone that may be associated with the reduced risk of breast cancer in obese premenopausal women is progesterone. Premenopausal obese women have reduced progesterone levels, believed to be due to an increased frequency of anovulation and a decreased production of progesterone in the luteal phase of their menstrual cycles (Henderson et al. 1985). This may contribute to a reduced risk of breast cancer in obese premenopausal women if the progesterone plus oestrogen theory is correct (see p. 400) (Key et al. 2001). Moreover, leptin levels inhibit ovarian oestrogen production and are found in higher levels in obese premenopausal women, and may be another contributing factor to the negative association between obesity and breast cancer risk in premenopausal women (Spicer \& Francisco, 1997; Petridou et al. 2000). 


\section{Fat distribution, sex hormones and breast cancer risk}

Hormone levels are greatly influenced not only by total fat mass (discussed earlier) but more significantly by fat distribution. The decreased synthesis of SHBG in overweight and obese women is predominantly linked to visceral obesity (Ballard-Barbash, 1994) and associated with hyperinsulinaemia (Kissebah \& Krakower, 1994). The consequence of this is an increased ratio of free:bound oestrogen and testosterone (Kissebah \& Krakower, 1994). The unbound, bioavailable oestrogen levels, as opposed to the total oestrogen levels, are believed to be the most significant in relation to breast cancer risk (Toniolo, 1997). In post-menopausal women the incidence of obesity increases and is often centrally distributed. This is in turn linked to higher levels of oestrogens produced from androgens in the adipocyte (Shifren \& Schiff, 2000) and decreased oestrogen-protein binding due to the reduction in SHBG, leading to higher bioavailable oestrone and 17- $\beta$-oestradiol (Bruning et al.1992; Maggino et al. 1993). Increased levels of bioavailable androgens are also linked to a central fat distribution and increase breast cancer risk directly through increasing breast cancer cell proliferation after binding to androgen receptors (Bryan et al. 1984), in addition to their influence on insulin sensitivity (discussed later, p. 404).

As discussed earlier, although obesity per se was reported to be weakly and inversely related to premenopausal breast cancer, central fat was positively linked with breast cancer risk in this group of women, although neither association was as strong as for post-menopausal breast cancer and adiposity. This anomaly of a negative association with obesity, but a weak positive association between central adiposity and premenopausal breast cancer risk, is difficult to explain but may be related to observed impacts of these body fat stores on sex hormone levels. It has been reported that premenopausal women with high visceral adiposity had higher levels of 17- $\beta$-oestradiol compared with peripherally obese women (Kirschner et al. 1990; De Pergola et al. 1996). In visceral fat androstenedione was preferentially converted into $5 \alpha$ reduced androgens (androsterone), which could be further metabolised to 17- $\beta$-oestradiol. However, in peripheral adipose tissue androstenedione is converted to oestrone. Since 17- $\beta$ oestradiol has been shown to be more carcinogenic than oestrone this may be a contributing factor in the increased risk for central adiposity and premenopausal breast cancer (De Pergola et al. 1996), although further research is required to clarify this.

The 'clearance' of androgens by adipocytes (mostly DHEA and androstenedione) in obese women is higher than in non-obese women, which explains why plasma levels of these hormones are usually normal despite increased ovarian production in obese premenopausal women (Schapira et al. 1991; Kissebah \& Krakower, 1994). In addition, hyperinsulinaemia, commonly associated with visceral fat deposition, has been reported to acutely increase the metabolic clearance rate of DHEA (but not DHEAS) in human subjects, resulting in a higher DHEAS:DHEA ratio (Nestler \& Kahwash, 1994). The adrenal androgen DHEA has been linked with a reduced risk of breast cancer, due to its metabolite (5-androstene-3, $17 \beta$-diole) acting as an oestrogen antagonist (Ebling \& Koivisto, 1994) and a reduction in the levels of DHEA or an increase in the DHEAS:DHEA ratio could conceivably be linked to an increased risk of breast cancer development. The relative levels of these adrenal androgens could contribute to the positive association found between central fat deposition and premenopausal breast cancer although further research is required to clarify this. However in support of this, it has been reported that in premenopausal women visceral fat was positively associated with plasma DHEAS:DHEA levels (De Pergola et al. 1996).

Central obesity has been linked to hyperandrogenism, particularly elevated testosterone, elevated bioavailable 17- $\beta$-oestradiol and lower SHBG levels (Kaaks \& Lukanova, 2001). In addition to these hormonal abnormalities, obesity and especially central adiposity are associ- 
ated with lipid irregularities, hyperinsulinaemia and insulin resistance, which are believed to be the central link to an increased risk of breast cancer through mechanisms outlined below.

\section{Lipids, insulin and breast cancer risk}

It has been well documented that hyperinsulinaemia and insulin resistance is associated with obesity (Nagata et al. 2000) and more so with central adiposity (Evans et al. 1984; Bruning et al. 1992; Lovegrove et al. 2002). Lipid abnormalities are also significantly and positively related to central adiposity in both pre- and post-menopausal women (Folsom et al. 1993; Lovegrove et al. 2002). Insulin concentrations in premenopausal women (Kaaks, 1996; Del Giudice et al. 1998) have been shown to be positively associated with breast cancer. Kaaks (1996) hypothesises that nutritionally induced hyperinsulinaemia and insulin resistance are the fundamental metabolic changes that result in breast cancer development (Fig. 1). Bruning et al. (1992) reported that C-peptide, a biological marker for insulin secretion, was associated with breast cancer risk, with higher C-peptide concentrations reported in breast cancer patients compared with controls (Bruning et al. 1992). Insulin has been shown to act as a growth factor for breast cancer (Pollak, 1998). There is also strong evidence that insulin is the central regulating factor for hepatic SHBG production (Toscano et al. 1992) and has been shown to inhibit the production of SHBG in liver cells (Plymate et al. 1990; Singh et al. 1990). There is also relatively strong evidence that elevated plasma concentrations of insulin are related to lower SHBG levels in obese women (Franks et al. 1991; Fendri et al. 1994).

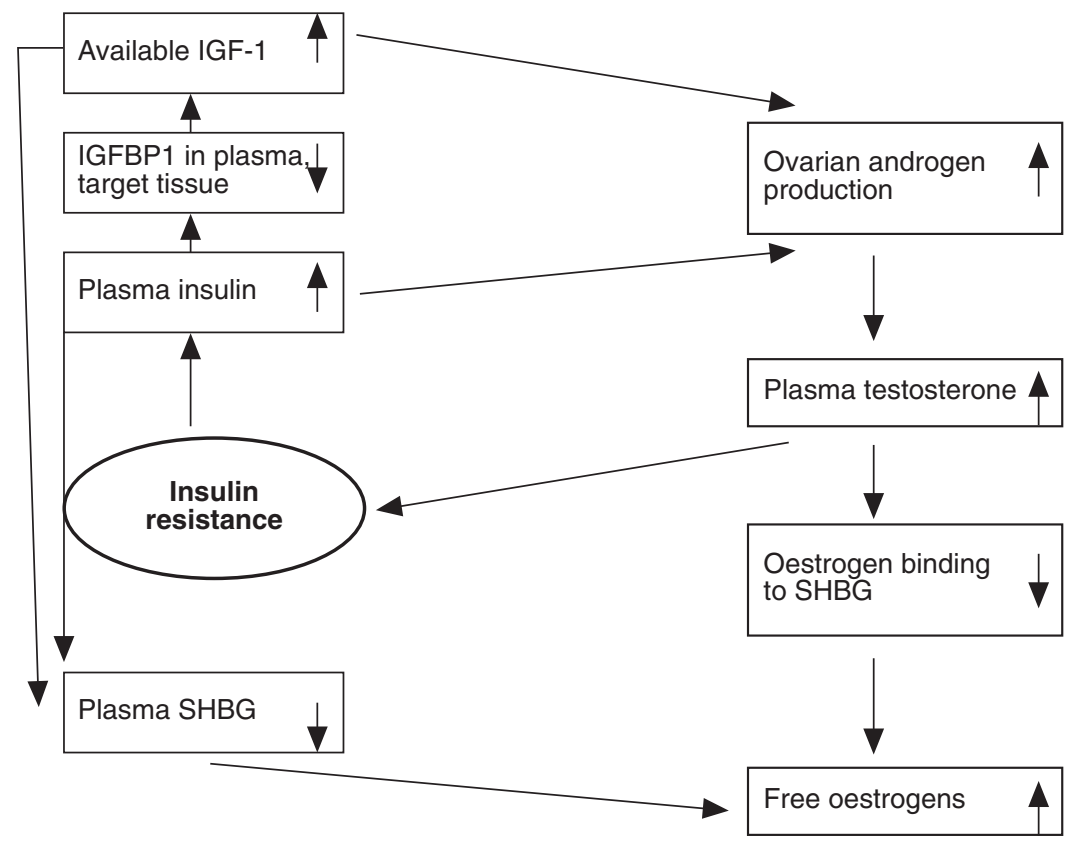

Fig. 1. The role of insulin resistance in the development of a hyperandrogenic endocrine profile. IGF-1, insulin-like growth factor-1; IGFBP1, insulin-like growth factor binding protein 1; SHBG, sex hormone-binding globulin (adapted from Kaaks, 1996). 
Lipid irregularities are also associated with obesity and insulin resistance. Fat deposits in the abdominal region, particularly around the viscera (i.e. omental) are subject to more rapid metabolism (Arner, 1995). In times of stress (physical activity, fasting) this fat depot releases high concentrations of non-esterified fatty acids (NEFA) (Groop et al. 1991). A number of studies show that the ability of insulin to suppress NEFA release in vivo is diminished in obese subjects (Groop et al. 1991; Minihane et al. 2000), probably due to the insulin resistance known to be associated with excess body fat accumulation, which is associated with a reduction in insulin receptors and an increase in hepatic lipid oxidation (Frayn, 1993). Elevated NEFA levels may also have a significant impact on breast cancer risk. NEFA are carried in the plasma bound to albumin, which also acts as a transport protein for circulating oestrogens. Due to the reduction in SHBG levels in central adiposity, an increased proportion of oestradiol will be carried associated with albumin. However, the elevated NEFA concentrations associated with central adiposity may be responsible for displacement of $17-\beta$-oestradiol from albumin due to a higher affinity and increased competition, resulting in further elevation of the bioavailable proportion of oestradiol within the plasma (Lovegrove \& Williams, 1997). Elevated NEFA concentrations may also contribute to the development of insulin resistance through the adverse effects of high hepatic NEFA concentrations on hepatic insulin extraction rates and indirectly increase breast cancer development by increasing insulin resistance (Frayn, 1993; Kaaks, 1996). Yet few studies have specifically investigated the relationship between NEFA, insulin resistance and breast cancer risk.

There are also contrasting hypotheses that relate insulin to hyperandrogenism. Until the late 1980s there was a predominant view that insulin resistance arose subsequent to an overproduction of ovarian androgens, especially testosterone (Evans et al. 1988). Direct mechanisms are not clear, but androgens may favour a more central body fat distribution (Kissebah et al. 1987) or mobilise NEFA from adipose tissue (Björntorp, 1994), which relates to the development of insulin resistance after long-term overeating, due to the adverse effects of high hepatic NEFA concentrations on hepatic insulin extraction rates (Kaaks, 1996). However in the early 1990s, a reversal in the causal relationship was proposed, namely that high insulin levels potentiate the luteinising hormone-stimulated production of ovarian steroids and particularly testosterone (Nestler \& Strauss, 1991). This suggests that insulin resistance, linked to central obesity, could directly increase testosterone concentrations, which may have a detrimental effect on breast cancer risk. To support this hypothesis is the evidence that insulin can directly affect SHBG production (Plymate et al. 1990; Singh et al. 1990; Toscano et al. 1992). The evidence for the association between insulin and breast cancer risk is strong. However an anomaly arises when the risk of breast cancer is investigated in women suffering from non-insulin-dependent diabetes (NIDDM). It has been reported that the risk of breast cancer in NIDDM women is no higher than those who do not suffer from NIDDM, despite the fact that NIDDM is associated with insulin resistance (Kaaks, 1996). The explanation for this is uncertain, but the association between diabetes and breast cancer may have divergent effects on pre- and post-menopausal breast cancer risk and no study has calculated risk according to menopausal status. Further studies are required.

\section{Insulin-like growth factors}

In addition to insulin, insulin-like growth factors (IGF; predominantly IGF-1) (which are synthesised by liver and target tissue, including adipose tissue) are also associated with increased breast cancer (Stoll, 1996; Kaaks \& Lukanova, 2001). Both insulin and IGF-1 have been shown to have growth-stimulatory effects on breast cancer cell lines (Oh et al. 1993; Pollak, 1998) and 
on proliferation mediated through IGF receptors (De Leon et al.1992) and by cross-talk between IGF-1 and oestrogens with regard to oestrogen receptors (Yee \& Lee, 2000). Like insulin, IGF-1 has a gonadotropic action, potentiating the production of steroid hormones, especially androgens, in the ovaries (Poretsky \& Kalin, 1987) and, like insulin, IGF-1 inhibits the hepatic production of SHBG (Plymate et al. 1990; Singh et al. 1990). Although plasma levels of IGF-1 are several hundred-fold higher than insulin they are generally bound to a number of specific proteins (IGF-binding proteins; IGFBP) and are therefore not bioavailable (Clemmons \& Underwood, 1991). Both IGF-1 and the predominant IGFBP, IGFBP-3, are regulated primarily by growth hormone. This is unlike IGFBP-1 levels, which follow the natural circadian variation shown by insulin and have been found to decrease after the infusion of glucose or insulin (Clemmons \& Underwood, 1991; Kaaks \& Lukanova, 2001). Moreover, in women with obesity, fasting insulin levels have been found to correlate negatively with IGFBP-1 (Weaver et al . 1990). In addition insulin has been shown to inhibit IGFBP-1 production in the liver (Singh et al. 1990). Therefore, a decrease in the concentration of IGFBP-1 may be associated with an increased bioactive IGF-1 at the level of the target tissue, the ovaries and breast. Thus it has been postulated that insulin may exert its negative effect on steroid hormone metabolism by increasing the bioavailable IGF-1 within the ovaries (Poretsky \& Kalin, 1987; Yee \& Lee, 2000; Kaaks \& Lukanova, 2001) (Fig. 1). In support of the relationship between IGF-1 and breast cancer it has been reported that premenopausal (Hankinson et al. 1998) and postmenopausal (Agurs-Collins et al. 2000) breast cancer cases were positively associated with IGF-1 concentrations.

\section{Fat tissue storage}

Fat tissue has the capacity to store fat-soluble circulating toxins, medications and certain vitamins, and stored toxins can act as a continuous source of toxins (Kohlmeier \& Kohlmeier, 1995). Thus women who have more body fat may be at higher risk of toxin exposure, especially if it is local fat stores of the breast (McTiernan, 2000). Conversely fat-soluble antioxidants such as vitamin A, D and E stored in fat could conceivably reduce risk.

\section{Future research}

Although there is a strong body of evidence for a positive relationship between obesity, especially adiposity centrally deposited, and post-menopausal breast cancer risk and a weaker negative relationship between obesity and premenopausal breast cancer, there is no doubt that more research is required to identify the exact mechanisms underlying these differential relationships. Priorities for future research include: a better and more direct measure of anthropometric measures; studies on the effects of these factors on risk of breast cancer throughout life with emphasis on ethnic minorities; intervention trials on weight-loss programmes and maintenance, diet and physical activity; research into biological mechanisms. Past clinical and biochemical studies have provided a basis for speculation into possible mechanisms, but plausible hypotheses that have emerged need to be tested by second-generation studies based on molecular mechanisms. One emerging interaction is that between IGF-1 receptors and oestrogen receptors, which is involved with stimulating the progression of carcinogenesis in both normal and neoplastic mammary tissue. This and other hypotheses should be tested in controlled clinical studies. 


\section{Conclusion}

An excess of dietary energy intake over energy expenditure leads to increases in BMI and eventually to obesity. BMI affects the development of hormone-dependent breast cancer, although the nature of the relationship varies between the two types that are determined by menopausal status and depends on age. In premenopausal women, obesity has been linked to a small reduction in sex hormones, including oestradiol and progesterone. A contributing factor to the effect of obesity on sex hormone levels is an increase in the frequency of anovular menstrual cycles, which may explain the small decrease in breast cancer that has been observed in some studies. However in post-menopausal women, obesity causes an increase in plasma concentrations of bioavailable oestradiol, known to increase the risk of breast cancer. Central adiposity has been positively associated with both premenopausal (although the evidence is limited) and postmenopausal breast cancer and has been linked to a state of hyperinsulinaemia and insulin resistance with the consequential effects on bioavailable oestradiol, androgens, IGF and specific hormone-binding proteins. Further research is required to determine the interrelationship between the aforementioned parameters and the precise mechanisms of actions. As obesity is one of the few modifiable risk factors that has been linked detrimentally to a number of chronic diseases, public health recommendations to maintain ideal weight throughout life are warranted.

\section{Acknowledgements}

The author would like to thank Professor Christine Williams for her helpful comments on this manuscript and Sean Lovegrove for his help with proof reading.

\section{References}

Agurs-Collins T, Adams-Campbell LL, Kim KS \& Cullen KJ (2000) Insulin-like growth factor-1 and breast cancer risk in postmenopausal African-American women. Cancer Detection and Prevention 24, 199-206.

Armellini F, Zamboni M, Perdichizzi G, Greco A, Napoli N, Pandolfo I, Mondello G \& Bosello O (1996) Computed tomography visceral adipose tissue volume measurements of Italians. Predictive equations. European Journal of Clinical Nutrition 22, 719-727.

Arner P (1995) Differences in lipolysis between human subcutaneous and omental adipose tissue. Annals of Medicine 27, 435-438.

Ballard-Barbash R (1994) Anthropometry and breast cancer. Cancer 74, 1090-1100.

Ballard-Barbash R, Schatzkin A, Carter CL, Kannel WB, Kreger BE, D’Agostino RB, Splansky GL, Anderson KM \& Helsel WE (1990) Body fat distribution and breast cancer in the Framingham study. Journal of the National Cancer Institute 82, 286-290.

Bergström A, Pisani P, Tenet V, Wolk A \& Adami HO (2001) Overweight as an avoidable cause of cancer in Europe. International Journal of Cancer 91, 421-430.

Bernstein L \& Ross RK (1993) Endogenous hormones and breast cancer risk. Epidemiologic Reviews 15, 48-65.

Berrino F, Muti P, Micheli A, Bolelli G, Krough V, Sciajno R, Pisani P, Panico S \& Secreto G (1996) Serum sex hormone levels after menopause and subsequent breast cancer. Journal of the National Cancer Institute 88, 291-296.

Björntorp P (1994) Fatty acids, hyperinsulinaemia and insulin resistance: which comes first? Current Opinions in Lipidology 5, 166-174.

Borrelli R, Isernia C, Di Biase G \& Contaldo F (1988) Mortality rates, causes and preventative factors of death in severely obese patients. International Journal of Vitamin and Nutrition Research 58, 343-350.

Brinton LA \& Swanson CA (1992) Height and weight at various ages and risk of breast cancer. Annals of Epidemiology 2, 597-609.

Bruning PF, Bonfrer JMG, van Noord PAH, Hart AAM, de Jong-Bakker M \& Nooijen WJ (1992) Insulin resistance and breast cancer risk. International Journal of Cancer 52, 511-516.

Bryan RM, Mercer RJ \& Bennett RC (1984) Androgen receptor in breast cancer. Cancer 54, 2436-2440.

Carroll KK (1975) Experimental evidence of dietary factors and hormone-dependent cancers. Cancer Research 3 , $253-271$. 
Carroll KK (1998) Obesity as a risk factor for certain types of cancers. Lipids 33, 1055-1059.

Choi NW, Howe GR, Miller AB, Matthews V, Morgan RW \& Munan L (1978) An epidemiological study of breast cancer. American Journal of Epidemiology. 107, 510-521.

Cleary MP \& Maihle NJ (1997) The role of body mass index in the relative risk of developing premenopausal versus postmenopausal breast cancer. Proceedings of the Society for Experimental Biology and Medicine 216, 28-43.

Clemmons DR \& Underwood LE (1991) Nutritional regulation of IGF-I and IGF-binding proteins. Annual Reviews of Nutrition 11, 393-412.

Cohen SM \& Ellwein LB (1990) Cell proliferation in carcinogenesis. Science 249, 1007-1011.

Cold S, Hansen S, Overvad K \& Rose C (1998) A women build and the risk of breast cancer. European Journal of Cancer 34, 1163-1174.

De Leon DD, Wilson DM, Powers M \& Rosenfeld RG (1992) Effects of insulin-like growth factors (IGFs) and IGF receptor antibodies on the proliferation of breast cancer cells. Growth Factors 6, 327-336.

Del Giudice ME, Fantus IG, Ezzat S, Mckeown-Eyssen G, Page D \& Goodwin PJ (1998) Insulin and related factors in premenopausal breast cancer risk. Breast Cancer Research and Treatment 47, 111-120.

den Tonkelaar I, Seidell JC \& Collette JA (1995) Body fat distribution in relation to breast cancer in women participating in the DOM-project. Breast Cancer Research and Treatment 34, 55-61.

den Tonkelaar I, Seidell JC, Collette HJ \& de Waard F (1992) Obesity and subcutaneous fat patterning in relation to breast cancer in postmenopausal women participating in the Diagnostic Investigation of Mammary Cancer Project. Cancer 69, 2663-2667.

Department of Health (1998) Nutritional Aspects of the Development of Cancer. Report of the working group on diet and cancer of the committee on medical aspects of food and nutrition policy, no. 48. London: The Stationery Office.

De Pergola G, Giorgino F, Garruti G, Cignarelli M \& Giorgino R (1996) Rapporto tra variabili antropometriche, ormoni sessuali e complicanze dell'obesità (Report of variable anthropometric measurements, sex hormones and complications of obesity). Metabolismo Oggi 13, 138-145.

De Waard F, Baanders-van Halewijn EA \& Huizinga J (1964) The bimodal age distribution of patients with mammary carcinoma. Cancer 17, 141-151.

Dorgan JF, Longcope C, Stephenson HE, Falk RT, Miller R, Franz C, Kahle L, Campbell WS, Tangrea JA \& Schatzkin A (1996) Relation of prediagnostic serum estrogen and androgen levels to breast cancer risk. Cancer Epidemiology Biomarkers and Prevention. 5, 533-539.

Dunn JF, Nisula BC \& Rodbard D (1981) Transport of steroid hormones: binding of 21 endogenous steroids to both testosterone-binding globulin and corticosteroid-binding globulin in human plasma. Journal of Clinical Endocrinology and Metabolism 53, 58-68.

Dupont WD \& Page DL (1987) Breast cancer risk associated with proliferative disease, age at first birth and a family history of breast cancer American Journal of Epidemiology 125, 769-779.

Ebling P \& Koivisto VA (1994) Physiological importance of dehydroepiandrosterone. Lancet 343, 1479-1481.

Egan KM, Newcomb PA, Titus-Ernstoff L, Trentham-Dietz A, Baron JA, Willet WC, Stampfer MJ \& Trichopoulos D (1999) The relation of breast size to breast cancer risk in postmenopausal women (United States). Cancer Causes and Control 10, 115-118.

Evans D, Hoffman RG, Kalkhoff RK \& Kissebah AH (1983) Relationship of androgenic activity to body fat topography, fat cell morphology, and metabolite aberrations in premenopausal women. Journal of Clinical Endocrinology and Metabolism 57, 304-310.

Evans DJ, Barth JH \& Burke CW (1988) Body fat topography in women with androgen excess. International Journal of Obesity 12, 157-162.

Evans DJ, Murray R \& Kissebah AH (1984) Relationship between skeletal muscle insulin resistance, insulin mediated glucose disposal and insulin binding: effects of obesity and body fat topography. Journal of Clinical Investigation 74, 1515-1524.

Fendri S, Arlot JM, Marcelli A, Dubreuil A \& Lalau JD (1994) Relationship between insulin sensitivity and circulating sex hormone-binding globulin levels in hyperandrogenic obese women. International Journal of Obesity 18, 755-759.

Folsom AR, Kaye SA, Prineas RJ, Potter JD, Gapstur SM \& Wallace RB (1990) Increased incidence of carcinoma of breast associated with abdominal adiposity in postmenopausal women. American Journal of Epidemiology 131, 794-803.

Folsom AR, Kaye SA, Sellers TA, Hong C-p, Cerhan JR, Potter JD \& Prineas RJ (1993) Body fat distribution and 5year risk of death in older women. Journal of the American Medical Association 269, 483-487.

Franks S, Kiddy DS, Hamilton-Fairley D, Bush A, Sharp PS \& Reed MJ (1991) The role of nutrition and insulin regulation of sex hormone binding globulin. Journal of Steroid Biochemistry and Molecular Biology 39, 835-838.

Frayn KN (1993) Insulin resistance and lipid metabolism. Current Opinions in Lipidology 4, 197-204.

Friedenreich CM (2001) Review of anthropometric factors and breast cancer risk. European Journal of Cancer Prevention 10, 15-32.

Groop LC, Saloranta C \& Shank M (1991) The role of free fatty acid metabolism in the pathogenesis of insulin resistance in obesity and non-insulin dependent diabetes mellitus. Journal of Clinical Endocrinology and Metabolism 72 , 96-107.

Hall HI, Coates RJ, Uhler RJ, Brinton LA, Gammon MD, Brogan D, Potischman N, Malone KE \& Swanson CA (1999) Stage of breast cancer in relation to body mass index and bra cup size. International Journal of Cancer 82, 23-27. 
Hall IJ, Newman B, Millikan RC \& Moorman PG (2000) Body size and breast cancer risk in black women and white women. American Journal of Epidemiology 151, 754-764.

Hankinson SE, Willet WC \& Colditz GA (1998) Circulating concentrations of insulin-like growth factor-I and risk of breast cancer. Lancet 351, 1393-1396.

Henderson BE, Ross RK, Judd HL, Krailo MD \& Pike MC (1985) Do regular ovulatory cycles increase breast cancer risk. Cancer 56, 1206-1208.

Higgins M, Kannel W, Garrison R, Pinsky J \& Stokes J (1989) III Hazards of obesity - the Framingham experience. Acta Medica Scandinavica 723, Suppl., 23-36.

Hislop TG, Coldman AJ, Elwood JM, Grauer G \& Kan L (1986) Childhood and recent eating patterns and risk of breast cancer. Cancer Detection and Prevention 9, 47-58.

Holmberg L, Ekbom A, Calle E, Mokdad A \& Byers T (1997) Breast cancer mortality in relation to self-reported use of breast self-examination. A cohort study of 450000 women. Breast Cancer Research and Treatment 43, 137-140.

House of Commons Public Accounts Committee (2002) House of Commons Public Accounts Committee Report on Tackling Obesity in England. House of Commons Paper no. 421. Session 2001/2002. 16 January 2002. London: The Stationery Office.

Hsieh C \& Trichopoulos D (1991) Breast size, handedness and breast cancer risk. European Journal of Cancer 27, $131-135$.

Huang Z, Hankinson SE \& Willet WC (1997) Dual effect of weight and weight gain on breast cancer risk. Journal of the American Medical Association 278, 1407-1411.

Huang Z, Willet WC, Colditz GA, Hunter DJ, Manson JE, Rosner B, Speizer FE \& Hankinson SE (1999) Waist circumference, waist:hip ratio, and risk of breast cancer in the Nurses' Health Study. American Journal of Epidemiology 150, 1316-1324.

Hunter DJ, Spiegelman D \& Adami H-O (1996) Cohort studies of fat intake and the risk of breast cancer - a pooled analysis. New England Journal of Medicine 334, 356-361.

Hunter DJ \& Willet WC (1993) Diet, body size, and breast cancer. Epidemiology Reviews 15, 110-131.

Ingam D, Nottage E, Ng S, Sparrow L, Roberts A \& Willcox D (1989) Obesity and breast disease. Cancer 64, 1049-1053.

Jones BA, Kasl SV, Curnen MGM, Owens PH \& Dubrow R (1997) Severe obesity as an explanatory factor for the black/white difference in stage at diagnosis of breast cancer. American Journal of Epidemiology 146, 394-404.

Kaaks R (1996) Nutrition, hormones, and breast cancer: Is insulin the missing link? Cancer Causes and Control 7 , 605-625.

Kaaks R \& Lukanova A (2001) Energy balance and cancer: the role of insulin and insulin-like growth factor-1. Proceedings of the Nutrition Society 60,91-106.

Kaaks R, Van Noord PAH, den Tonkelaar I, Peeters PHM, Riboli E \& Grobbee DE (1998) Breast-cancer incidence in relation to height, weight and body fat distribution in the Dutch DOM cohort. International Journal of Cancer $\mathbf{7 6}$, 647-651.

Kaye SA, Folsom AR, Soler JT, Prineas RJ \& Potter JD (1991) Associations of body mass and fat distribution with sex hormone concentrations in postmenopausal women. International Journal of Epidemiology 20, 151-156.

Kelsey JL \& Bernstein L (1996) Epidemiology and prevention of breast cancer. Annual Review of Public Health 17, 47-67.

Key TJ, Allen NA, Verkasalo PK \& Banks E (2001) Energy balance and cancer: the role of sex hormones. Proceedings of the Nutrition Society 60, 81-89.

Key TJA \& Pike MC (1988) The role of oestrogens and progestogens in the epidemiology and prevention of breast cancer. Journal of Cancer and Clinical Oncology 24, 29-43.

Kirschner MA, Samojlik E, Drejka M, Szmal E, Schneider G \& Ertel N (1990) Androgen-estrogen metabolism in women with upper body versus lower body obesity. Journal of Clinical Endocrinology and Metabolism 70, $473-479$.

Kissebah AH \& Krakower GR (1994) Regional adiposity and morbidity. Physiology Reviews 74, 761-811.

Kissebah AH, Pieris A \& Evans DJ (1987) Mechanisms associating body fat distribution with the abnormal metabolic profile in obesity. Recent Advances in Obesity Research 5, 54-59.

Kohlmeier L \& Kohlmeier M (1995) Adipose tissue as a medium for epidemiologic exposure assessment. Environmental Health Perspective 103, 99-106.

Krotkiewski M, Seidall JC \& Björntorp P (1990) Glucose tolerance and hyperinsulinaemia in obese women: role of adipose tissue distribution, muscle fiber characteristics and androgens. Journal of International Medicine 228, $385-392$.

Kumar NB, Lyman GH, Allen K, Cox CE \& Schapira DV (1995) Timing of weight gain and breast cancer risk. Cancer 76, 243-249.

La Vecchia C, Negri E, Franceschi S, Talamini R, Bruzzi P, Palli D \& Decarli A (1997) Body mass index and postmenopausal breast cancer: an age-specific analysis. British Journal of Cancer 75, 441-444.

Lea AJ (1966) Dietary factors associated with death-rates from certain neoplasms in man. Lancet ii, 332-333.

Le Marchand L, Kolonel LN, Earl ME \& Mi M-P (1988) Body size at different periods of life and breast risk. American Journal of Epidemiology 128, 137-152.

Liehr JG (2000) Is estradiol a genotoxic mutagenic carcinogen? Endocrine Reviews 21, 40-54.

London SJ, Colditz GA, Stampfer MJ, Willet WC, Rosner BR \& Speizer FE (1989) Prospective study of relative weight, height and risk of breast cancer. Journal of the American Medical Association 262, 2853-2858. 
Lovegrove JA, Silva KDRR, Wright JW \& Williams CM (2002) Adiposity, insulin and lipid metabolism in postmenopausal women. International Journal of Obesity (In the Press).

Lovegrove JA \& Williams CM (1997) Diet and breast cancer. Breast Cancer 9, 35-39.

Mackenzie I (1955) The production of mammary cancer in rats using oestrogens. British Journal of Cancer $\mathbf{9}$, 284-299.

McTiernan A (2000) Association between energy balance and body mass index and risk of breast carcinoma in women from diverse racial and ethnic backgrounds in the US. Cancer 88, 1248-1255.

Maggino T, Pirrone F, Velluti F \& Bucciante G (1993) The role of endocrine factors and obesity in hormone dependent gynecological neoplasias. European Journal of Gynaecology and Oncology 14, 119-126.

Magnusson C, Baron J, Persson I, Wolk A, Bergstrom R, Trichopoulos D \& Adami HO (1998) Body size in different periods of life and breast cancer risk in postmenopausal women. International Journal of Cancer 76, 29-34.

Männistö S, Pietinen P, Pyy M, Palmgren J, Eskelinen M \& Uusitupa M (1996) Body size indicators and risk of breast cancer according to menopause and estrogen-receptor status. International Journal of Cancer 68, 8-13.

Minihane AM, Khan S, Talmud PJ, Williams DL, Wright JW, Murphy MC, Griffin BA \& Williams CM (2000) Lack of association between lipaemia and central adiposity in subjects with an atherogenic lipoprotein phenotype (ALP). International Journal of Obesity 24, 1097-1106.

Molarius A \& Seidell JC (1998) Selection of anthropometric indicators for classification of abdominal fatness - a critical review. International Journal of Obesity 22, 719-727.

Moller H, Mellengaard A, Lindvig K \& Olsen JH (1994) Obesity and cancer risk: A Danish record-linkage study. European Journal of Cancer 30A, 344-350.

Monninkhof EM, van der Schouw YT \& Peeters PHM (1999) Early age at menopause and breast cancer: are leaner women more protected? A prospective analysis of the Dutch DOM cohort. Breast Cancer Research and Treatment 55, 285-291.

Moore DH (1983) Breast carcinoma etiological factors. Advanced Cancer Research 40, 189-253.

Muti P, Stanulla M, Micheli A, Krogh V, Freudenheim JL, Yang J, Schunemann HJ, Trevisan M \& Berrino F (2000) Markers of insulin resistance and sex steroid hormone activity in relation to breast cancer risk: a prospective analysis of abdominal adiposity, sebum production, and hirsutism. Cancer Causes and Control 11, 721-730.

Nagata C, Shimizu H, Takami R, Hayashi M, Takeda N \& Yasuda K (2000) Relations of insulin resistance and serum concentrations of estradiol and sex hormone-binding globulin to potential breast cancer risk factors. Japanese Journal of Cancer Research 91, 948-953.

Nestler JE \& Kahwash Z (1994) Sex-specific action of insulin acutely increases the metabolic clearance rate of dehydroepiandrosterone in humans. Journal of Clinical Investigations 94, 1484-1489.

Nestler JE \& Strauss JF (1991) Insulin as an effector of human ovarian and adrenal steroid metabolism. Endocrinology Metabolism of Clinical North America 20, 807-823.

Ng E-H, Gao F, Ji C-H, Ho G-H \& Soo K-C (1997) Risk factors for breast carcinoma in Singaporean Chinese women. Cancer 80, 725-731.

Oh Y, Muller HL, Lamson G \& Rosenfeld RG (1993) Insulin-like growth factor (IGF)-independent action of IGF-binding protein 3 in Hs578T human breast cancer cells. Journal of Biological Chemistry 268, 14964-14971.

Paffenbarger RS Jr, Kampert JB \& Chang H-G (1980) Characteristics that predict risk of breast cancer before and after the menopause. American Journal of Clinical Nutrition 112, 258-268.

Pathak DR \& Whittemore AS (1992) Combined effects of body size, parity and menstrual events on breast cancer incidence in seven countries. American Journal of Epidemiology 135, 153-168.

Peacock SL, White E, Daling JR, Voigt LF \& Malone KE (1999) Relation between obesity and breast cancer in young women. American Journal of Epidemiology 149, 339-346.

Petrek JA, Peters M, Cirrincione C, Rhodes D \& Bajorunas D (1993) Is body fat topography a risk factor for breast cancer? Annals of Internal Medicine 118, 356-362.

Petridou E, Papadiamantis Y, Markopoulos C, Spanos E, Dessypris N \& Trichopoulos D (2000) Leptin and insulin growth factor 1 in relation to breast cancer (Greece). Cancer Causes and Control 11, 383-388.

Plymate SR, Hoop RC, Jones RE \& Matej LA (1990) Regulation of sex hormone-binding globulin production by growth factors. Metabolism 39, 967-970.

Pollak MN (1998) Endocrine effects of IGF-I on normal and transformed breast epithelial cells: Potential relevance to strategies for breast cancer treatment and prevention. Breast Cancer Research and Treatment 47, $209-217$.

Poretsky L \& Kalin MF (1987) The gonadotropic function of insulin. Endocrinology Reviews 8, $132-141$.

Potischman N, Hoover RN, Brinton LA, Siiteri P, Dorgan JF, Swanson CA, Berman ML, Mortel R, Twiggs LB, Barrett RJ, Wilbanks GD, Persky V \& Lurain JR (1996) Case-control study of endogenous steroid hormones and endometrial cancer. Journal of the National Cancer Institute 88, 1127-1135.

Schapira DV, Kumar NG, Lyman GH \& Cox CE (1990) Abdominal obesity and breast cancer risk. American College of Physicans 112, 182-186.

Schapira DV, Kumar NG, Lyman GH \& Cox CE (1991) Obesity and body fat distribution and breast cancer prognosis. Cancer 67, 523-528.

Schapira DV, Wolff PA, Kumar NB, Anderson JJB, Aziz NM, Lyman GH \& Swanson M (1994) The effect of weight loss on estimated breast cancer risk and sex hormone levels. Oncology Reports 1, 613-617.

Secreto G \& Zumoff B (1994) Abnormal production of androgens in women with breast cancer. Anticancer Research 14, 2113-2117. 
Sellers TA (1997) Genetic factors in the pathogenesis of breast cancer: Their role and relative importance. Journal of Nutrition 127, 929S-932S.

Sellers TA, Kushi LH \& Potter JD (1992) Effect of family history, body fat distribution, and reproductive factors on the risk of post-menopausal breast cancer. New England Journal of Medicine 326, 1323-1329.

Shi YE, Liu YE, Lippman ME \& Dickson RB (1994) Progestins and antiprogestins in mammary tumour growth and metastasis. Human Reproduction 9, 162-173.

Shifren JL \& Schiff I (2000) The aging ovary. Journal of Women's Health and Gender Based Medicine 9, S3-S7.

Shu XO, Jin F, Dai Q, Shi JR, Potter JD, Brinton LA, Hebert JR, Ruan ZX, Gao YT \& Zheng W (2001) Association of body size and fat distribution with risk of breast cancer among Chinese women. International Journal of Cancer $\mathbf{9 4}$, 449-455.

Siiteri PK \& MacDonald PC (1973) Role of extraglandular oestrogen in human endocrinology. In Handbook of Physiology, pp. 615-629 [SR Geiger, EB Astwood and RO Greep, editors]. Washington, DC: American Physiological Society.

Singh A, Hamilton-Fairley D \& Koistinen R (1990) Effect of insulin-like growth factor-type I (IGF-I) and insulin on the secretion of sex-hormone binding globulin and IGF-I binding globulin (IBP-I) by human hepatoma cells. Journal of Endocrinology 124, R1-R3.

Sonnenschein E, Toniolo P, Terry MB, Bruning PF, Kato I, Koenig KL \& Shore RE (1999) Body fat distribution and obesity in pre- and post-menopausal breast cancer. International Journal of Epidemiology 28, 1026-1031.

Spicer LJ \& Francisco CC (1997) The adipose gene product, leptin: evidence of a direct inhibitory role in ovarian function. Endocrinology 135, 3374-3379.

Stoll BA (1995) Timing of weight gain in relation to breast cancer risk. Annals of Oncology 6, 245-248.

Stoll BA (1996) Obesity, social class and Western diet: A link to breast cancer prognosis. European Journal of Cancer 32A, 1293-1295

Stoll BA (1999) Perimenopausal weight gain and progression of breast cancer precursors. Cancer Detection and Prevention 23, 31-36.

Stoll BA \& Secreto G (1992) New hormone-related markers of high risk to breast cancer. Annals of Oncology 3, 435-438.

Swanson CA, Brinton LA, Taylor PR, Licitra LM, Zeigler RG \& Schairer C (1989) Body size and breast cancer risk assessed in women participating in the Breast Cancer Detection Demonstration Project. American Journal of Epidemiology 130, 1133-1141.

Swanson CA, Jones DY, Schatzkin A, Briton LA \& Zeigler RG (1988) Breast cancer risk assessed by anthropometry in NHANES I Epidemiological follow-up study. Cancer Research 48, 5363-5367.

Tannenbaum A (1942) The genesis and growth of tumours. iii Effects of a high fat diet. Cancer Research 2, 468-475.

Toniolo PG (1997) Endogenous estrogens and breast cancer risk: the case for prospective cohort studies. Environmental Health Perspective??? 105, 587-592.

Toniolo PG, Levitz M, Zeleniuch-Jacquotte A, Banerjee S, Koenig KL, Shore RE, Strax P \& Pasternack BS (1995) A prospective study of endogenous estrogens and breast cancer in postmenopausal women. Journal of the National Cancer Institute 87, 190-197.

Tornberg SA \& Carstensen JM (1994) Relationship between Quetelet's index and cancer of breast and female genital tract in 47000 women followed for 25 years. British Journal of Cancer 69, 358-361.

Toscano V, Balducci P, Mangiantini A \& Sciarra F (1992) Steroidal and non-steroidal factors in plasma sex hormone binding globulin regulation. Journal of Steroidal Biochemistry and Molecular Biology 43, 431-437.

Trentham-Dietz A, Newcomb PA, Egan KM, Titus-Ernstroff L, Baron JA, Storer BE, Stampfer M \& Willet WC (2000) Weight change and risk of post-menopausal breast cancer (United States). Cancer Causes and Control 11, 533-542.

Trentham-Dietz A, Newcomb PA \& Storer BE (1997) Body size and risk of breast cancer. American Journal of Epidemiology 145, 1011-1019.

Ursin G, Longnecker MP, Haile RW \& Greenland S (1995) A meta-analysis of body mass index and risk of premenopausal breast cancer. Epidemiology 6, 137-141.

Van den Brandt PA, Dirx MJM, Ronckers CM, van den Hoogen P \& Goldbohm RA (1997) Height, weight, weight change and postmenopausal breast cancer risk: the Netherlands Cohort Study. Cancer Causes and Control 8, 39-47.

Van den Brandt PA, Spiegelman D, Yaun S-S, Adami HO, Beeson L, Folsom AR, Fraser G, Goldbohm RA, Graham S, Kushi L, Marshall JR, Miller AB, Rohan T, Smith-Warner SA, Speizer FE, Willet WC, Wolk A \& Hunter DJ (2000) Pooled analysis of prospective cohort studies on height, weight and breast cancer risk. American Journal of Epidemiology 152, 514-527.

van Noord PAH, Seidell JC, den Tonkelaar I, Baanders-van Halewijn EA \& Ouwehand IJ (1990) The relationship between fat distribution and some chronic diseases in 11825 women participating in the DOM-project. International Journal of Epidemiology 19,564-570.

Vatten LJ \& Kvinnsland S (1990) Body mass index and risk of breast cancer. A prospective study of 23826 Norwegian women. International Journal of Cancer 45, 440-444.

Verkasalo PK, Thomas HV, Appleby PN, Davey GK \& Key TJ (2001) Circulating levels of sex hormones and their relation to risk factors for breast cancer: a cross-sectional study in 1092 pre-menopausal and post-menopausal women. Cancer Causes and Control 12, 47-59.

Weaver JU, Holly JMP, Kopelman PG, Noonan K, Giadom CG, White N, Virdee S \& Wass JAH (1990) Decreased sex hormone binding globulin (SHBG) and insulin-like growth factor binding protein (IGFBP-1) in extreme obesity. Clinical Endocrinology 33, 415-422. 
Wee CC, McCarthy EP, David RB \& Philips RS (2000) Screening for cervical and breast cancer: Is obesity an unrecognized barrier to preventive care? Annals of Internal Medicine 132, 697-700.

Willet WC, Browne ML, Bain C, Lipnick RJ, Stampfer MJ \& Rosner B (1985) Relative weight and risk of breast cancer among premenopausal women. American Journal of Epidemiology 122, 731-740.

Wolk A, Gridley G, Svensson M, Nyren O, McLaughlin JK, Fraumeni JF \& Adami HO (2001) A prospective study of obesity and cancer risk (Sweden). Cancer Causes and Control 12, 13-21.

Yee D \& Lee AV (2000) Crosstalk between the insulin-like growth factor and estrogens in breast cancer. Journal of Mammary Gland Biology and Neoplasia 5, 107-115.

Yong LC, Brown CC, Schatzkin A \& Schairer C (1996) Prospective study of relative weight and risk of breast cancer: The Breast Cancer Detection Demonstration Project Follow-up Study 1979-1987-1989. American Journal of Epidemiology 143, 985-995.

Zamboni M, Armellini F, Harris T, Turcato E, Micciolo R, Bergamo-Andreis IA \& Bosello O (1997) Effects of age on body fat distribution and cardiovascular risk factors in women. American Journal of Clinical Nutrition 66, 111-115.

Ziegler RG, Hoover RN, Pike MC, Hildesheim A, Normura AMY, West DW, Wu-Williams AH, Kolonel LN, HornRoss PL, Rosenthal JF \& Hyer MB (1996) Migration patterns and breast cancer risk in Asian-American women. Journal of the National Cancer Institute 85, 1819-1827.

Zumoff B (1988) Hormonal profiles in women with breast cancer. Anticancer Research 8, 627-636. 